\title{
The Sexual Behaviour of Chagas' Disease Vectors: Chemical Signals Mediating Communication between Male and Female Triatomine Bugs
}

\author{
Gabriel Manrique $^{1}$ and Marcelo Lorenzo ${ }^{2}$ \\ ${ }^{1}$ Laboratorio de Fisiología de Insectos, Departamento de Biodiversidad y Biología Experimental, \\ Facultad de Ciencias Exactas y Naturales, Universidad de Buenos Aires, C1428EHA Ciudad Autónoma de Buenos Aires, Argentina \\ ${ }^{2}$ Laboratory of Triatomines and Chagas' Disease Epidemiology, René Rachou Institute, FIOCRUZ, 30190-002 Belo Horizonte, \\ MG, Brazil
}

Correspondence should be addressed to Gabriel Manrique, gabo@bg.fcen.uba.ar

Received 23 September 2011; Revised 20 December 2011; Accepted 3 January 2012

Academic Editor: Jocelyn G. Millar

Copyright ( 2012 G. Manrique and M. Lorenzo. This is an open access article distributed under the Creative Commons Attribution License, which permits unrestricted use, distribution, and reproduction in any medium, provided the original work is properly cited.

\begin{abstract}
Chemical communication mechanisms that mediate sexual behaviour in triatomine bugs are reviewed with regard to source, identity, and function of sex pheromones. Males attempt to copulate but may be rejected, depending on female age and nutritional status. Triatomine males locate partners through sex pheromones emitted by the metasternal glands (MGs) of females. These activate males, inducing them to leave their refuges and initiate flight. Wandering males display anemotactic orientation modulated by chemical signals emitted from female MGs. Analyses of the MG secretions of several species resulted in the identification of numerous ketones, acetals, and alcohols. Occlusion experiments showed that Brindley's gland products were not required for mating. Metasternal gland volatiles are emitted by virgin male and female bugs, with detection over females occurring more consistently, especially during the early scotophase, suggesting female calling behaviour. Mating triatomine females have been reported to attract males that tend to copulate successively with them. Mating males prolong mating and postcopulatory mate guarding in the presence of other males. This is indicative of a polyandrous mating system in several triatomine species. Its potential advantages remain unknown, and comparative studies are required to increase our understanding of triatomine reproductive strategies.
\end{abstract}

\section{Introduction}

Triatomine bugs have great epidemiological relevance because they transmit Trypanosoma cruzi Chagas 1909, the etiological agent of Chagas' disease [1-3]. This disease afflicts $\sim 15$ million people, with a further 75-90 million at risk from potential transmission in Latin America [4]. The vectorial capacity of these insects relies largely on their ability to invade habitations and develop large colonies, coupled with their being efficient intermediate hosts of trypanosomes. The risk of transmission is greatly enhanced in the case of poorly maintained thatch and mud houses where cracks provide abundant shelter in close proximity to humans and their domestic animals. Vector control is currently the only feasible means of reducing Chagas' disease transmission because of the lack of vaccines and effective therapeutic drugs [4].

Triatomine bugs have been shown to use a diverse range of chemical cues and signals to detect their hosts and communicate with conspecifics, respectively [5]. Hostrelated cues include stimuli such as body heat, $\mathrm{CO}_{2}$, and volatile compounds from the skin and breath [6]. Insects in this group also utilize pheromones for marking refuges, locating mates, and for alerting conspecifics to danger [5]. The following sections review our current knowledge of triatomine chemical communication, particularly with regard to reproductive behaviours. 


\section{Triatomine Mating Behaviour}

The mating behaviour of several triatomine species has been described in detail [7-12]. The general mating pattern is similar across species and consists of several behavioural steps performed by males. Initially, a male approaches and either jumps onto or slowly mounts a female. The male then places itself in a dorsolateral position in relation to the female. Once in this position, the male grasps the female, both dorsally and ventrally using all three pairs of legs, releases its paramers, and immobilizes the genitalia of the female to allow the introduction of the aedeagus. The duration of copulation varies between species, ranging from ca. $6 \mathrm{~min}$ for Triatoma infestans Klug, 1834, to ca. $50 \mathrm{~min}$ for Rhodnius prolixus Stål, 1859 [12]. Even after the genitalia of both insects are separated, the males occasionally remain on top of females for several minutes.

Males may perform several copulatory attempts with the same female in order to engage in mating. These copulatory attempts are not always successful because female receptivity depends on age and nutritional status, among other factors [8-10]. Females can display different rejection behaviours in response to copulation attempts [8-10]. These include flattening (the female lowers her body against the substrate to prevent a male from moving into the copulatory position), abdominal movements (females shake their bodies up and down), evasion (females walk away), and stridulation (females rub the tip of their rostrum against the prosternal groove) [12]. The term male-deterring stridulation has been used to describe this behaviour by nonreceptive females. This behaviour has been reported as source of a substrate-borne signal which plays a role in intraspecific communication in $T$. infestans and $R$. prolixus $[13,14]$.

It has been demonstrated that odours from the metasternal glands promote mating in $T$. infestans and $R$. prolixus [ 15 , 16]. In addition to the volatile compounds secreted by the metasternal glands, it has been suggested that epicuticular lipids may play a role as female recognition signals (i.e., contact pheromones) in T. Infestans, but this needs to be confirmed [17].

\section{Signals Mediating Copulation Behaviours}

Following moulting to the adult stage, triatomine bugs search for host cues to obtain blood meals for nutrition and egg development by females, but they also need to find mates as they become sexually mature. The various species in this subfamily inhabit diverse sylvatic habitats where they associate with vertebrates. Both immatures and adults usually feed at night on a wide array of warm- and cold-blooded animals such as birds, mammals, reptiles, and amphibians. Generally, ecotopes such as birds' nests offer limited and unpredictable access to blood, for example, due to seasonal chick rearing. In addition, coinhabiting the den of a mammal or a bird's nest with a host represents an increased predation risk. Such circumstances might have induced the evolution of the strong tendency of triatomines to hide in cracks and crevices, at the cost of simultaneously affecting the chances of finding mates.
The location, frequency, and timing of mating in triatomines remain unknown, but it is likely that mating occurs around dusk when general locomotion patterns are enhanced [18]. Similarly, bugs probably leave their refuges to search for mates around this time, and it is likely that chemical signals could mediate mate location (see the following). In fact, without long distance signals to mediate encounters between males and females, reproduction would be limited to small sylvatic colonies where adult pairs coexist.

Recently it has been shown that males of two triatomine species are stimulated to leave their shelters by femaleproduced volatile signals $[19,20]$. Interestingly, males may attempt copulation with other males, and according to these authors, this tendency is greatly increased in the presence of chemical signals emitted by the female. These results indicate that odours from the female act as activators, attractants, and aphrodisiacs.

Many authors have attempted to determine whether triatomine bugs use chemical signals to communicate between sexes, often with contradictory results which in many cases are difficult to interpret or place in context due to methodological flaws. For example, Antich [21] reported the attraction of adult $R$. prolixus to volatile pheromones. Later, Neves and Paulini [22] presented similar results describing sexual attraction mediated by chemical signals in adult T. infestans and Panstrongylus megistus Burmeister, 1835. Additionally, Ondarza and collaborators $[23,24]$ presented results indicating that a volatile signal mediated the sexual behaviour of T. mazzotti Usinger, 1941, but conflicting results were subsequently presented by Rojas and collaborators [25]. Closer inspection of some of these pioneering studies suggests that the experimental designs might not have been sufficient to be able to conclude that chemical signals were mediating encounters between males and females.

Many years later, Brindley's glands became the target of several studies aimed at elucidating communication between adult triatomine bugs. Fontan and collaborators [26], as well as Guerenstein and Guerin [27], presented results showing that a subset of the compounds in Brindley's glands could be recovered from the headspace over groups of copulating $T$. infestans and R. prolixus, respectively. The first report provided evidence of behavioural or electrophysiological effects of single components from the secretion of Brindley's glands on adult triatomines. However, it remains unclear whether these effects are related to reproductive behaviours, given that the elicitation of an electrophysiological response or a change in the level of activity does not necessarily indicate a sexual role for the compounds tested. Even attraction of adults to single compounds is not a certain demonstration of a sexual role, unless only one sex is attracted and immatures do not display similar behavioural responses. Two additional points weaken the argument that Brindley's gland products are related to sexual behaviour. First, Brindley's glands are the proposed source of alarm pheromones in all species in the subfamily [28-30], including $R$. prolixus, T. infestans, T. phyllosoma, P. megistus, T. maculata, T. brasiliensis, and T. vitticeps. Therefore, the inadvertent release of Brindley's gland compounds by handling bugs before or during bioassays may have confounded the results of those 
assays, and in fact, some of the studies suggesting a sexual role for Brindley's glands secretions did not report how they avoided the emission of the alarm pheromone while handling bugs. Second, reports proposing such a role for Brindley's gland odours have used groups of adults for odour collection; however it is uncertain whether similar results can be obtained when working with pairs of insects, the basic unit of reproductive behaviour. Addressing these questions may help to clarify unresolved issues in the study of triatomine sexual communication.

\section{Chemical Signals Mediating Possible Attraction between Adult Triatomine Bugs}

It had been suggested that males of several triatomine species might be captured more frequently in light traps than females [31], and this proved to be the case with light trapping of T. infestans in Northern Argentina [32]. A recent report also suggested a link between male flight initiation and sexual communication for $R$. prolixus [33], indicating that males may undergo dispersal flights as a mechanism for locating females via volatile chemical signals. Zacharias and collaborators [33] have shown that $R$. prolixus females emit volatile compounds that induce males to initiate flight, and that these compounds are likely associated with the metasternal glands. In addition, these authors showed that excised metasternal glands elicited similar responses from males, confirming that these glands are the source of a volatile signal from the female. A similar increase in take-off frequency was also observed for male T. brasiliensis Neiva, 1911, when presented airstreams containing female odour [19]. Females of both species showed no response to male odours. Preliminary results with T. vitticeps Stål, 1859, have shown that males of this species only engage in flight if volatile signals emitted by females are present (H.H.R. Pires, personal communication). It is also worth noting that flight initiation by males has a clear directional component, with males typically flying upwind [33]. The introduction of female metasternal gland odours into an airstream only induces an increase in male take-off frequency. However, the female-produced chemicals that cause this increase remain unknown.

\section{Attraction between Walking Adult Triatomine Bugs}

In addition to flying, triatomine adults may detect and walk towards sexual partners from a distance. Whereas the reaction of males to the presence of odours from females has already been described, two recent publications investigated the anemotactic responses of wandering males. Vitta and collaborators [34] used an olfactometer to show that male T. brasiliensis move upwind in airstreams laden with the odour of females, exhibiting odour-modulated anemotaxis in response to a sexual pheromone. In addition, they reported that the bioactive compounds were associated with metasternal gland products from females. Interestingly, males also exhibited similar responses in the presence of airstreams containing odours from males. However, blocking the metasternal gland orifices of the males used as the stimulus source did not impair the response of tested males, suggesting that the test males were responding to odours from a different source, and possibly being used in a different context. In contrast, $T$. brasiliensis females showed no response to odours from either sex.

A different experimental approach allowed Pontes [20] to show that $R$. prolixus males are attracted and orient towards airstreams laden with the odour of females. This study used a locomotion compensator [35] to evaluate the responses of males and females presented with odours from adult bugs of either sex. The study showed that $R$. prolixus males were attracted by volatile compounds from the metasternal glands of females.

\section{The Role of Triatomine Exocrine Gland Secretions}

Most Reduviidae have several exocrine glands in the thorax and abdomen, such as the metasternal glands, Brindley's glands, dermal glands, ventral glands, and abdominal glands $[38,39]$. Ventral and abdominal glands are apparently absent in the subfamily Triatominae, and only adult insects possess both metasternal and Brindley's glands [40]. The paired metasternal glands are widespread among the Heteroptera. They are ventrally located at the anterior margin of each metacoxal cavity [41]. Each gland consists of an unbranched secretory tubule and a small pear-shaped reservoir opening laterally to the sternal apophyseal pit $[42,43]$. The sac-like paired Brindley's glands are dorsally located, extending into the lateral portion of the second abdominal segment and opening onto the metathoracic epimeron [39, 41, 44, 45]. These glands, which secrete isobutyric acid as their most abundant product, are likely to be associated with alarm and defense functions $[29,30,45,46]$. As stated previously, it has also been suggested that compounds produced by Brindley's glands are involved in sexual signalling in triatomines [26, 27, 45]. However, no behavioural evidence has been reported that associates compounds from Brindley's glands with behavioural responses specifically related to sex. Further investigation is required to clarify the role of Brindley's glands secretions in the reproductive behaviour of triatomines.

The secretion from the metasternal glands contains several compounds, some of which are highly volatile aliphatic ketones and alcohols (Table 1). The first compound identified from these glands, 3-methyl-2-hexanone, from Dipetalogaster maxima (Uhler, 1894), may function as an alarm pheromone or defensive secretion [36] and can be detected when bugs of this species are disturbed [27]. Volatile components emitted from these glands have now been identified in other triatomine species such as $T$. infestans, $R$. prolixus, and T. brasiliensis. Table 2 summarizes metasternal gland compounds detected in the headspace odours of triatomine bugs in different behavioural contexts. As mentioned, it has been proposed that metasternal gland components may mediate sexual communication between 
TABLE 1: Compounds identified from metasternal glands of different triatomine species (references cited in brackets).

\begin{tabular}{|c|c|c|c|c|c|}
\hline & D. maxima [36] & T. infestans [30] & R. prolixus [16] & T. brasiliensis [34] & $\begin{array}{l}\text { T. brasiliensis } \\
\text { T. infestans [37] }\end{array}$ \\
\hline 2-butanone & & + & + & + & \\
\hline 2-pentanone & & & + & & \\
\hline (S)-2-butanol & & & + & + & \\
\hline (R)-2-pentanol & & & & + & \\
\hline 2-methyl-3-buten-2-ol & & & + & & \\
\hline 3-methyl-2-butanol & & & + & & \\
\hline 3-pentanone & & + & & + & \\
\hline 3-methyl-2-hexanone & + & & & & \\
\hline 3-pentanol & & + & + & + & \\
\hline (S)-2-pentanol & & & + & & \\
\hline (E)-2-methyl-3-penten-2-ol & & & + & & \\
\hline (S)-4-methyl-2-pentanol & & & + & & \\
\hline (S)-3-hexanol & & & + & + & \\
\hline (R)-3-hexanol & & & & + & \\
\hline 3-methyl-2-hexanol & & & & + & \\
\hline (R)-4-methyl-1-hexanol & & & & + & \\
\hline 3-hexanol & & + & & & \\
\hline 2-methyl-1-propanol & & & & + & \\
\hline 2-methyl-1-butanol & & + & + & & \\
\hline (S)-2-methyl-1-butanol & & & & + & \\
\hline 4-methyl-3-penten-2-ol & & & + & & \\
\hline 1-heptanol & & & & + & \\
\hline 6-methyl-1-heptanol & & & & + & \\
\hline (R)-4-methyl-1-heptanol & & & & + & \\
\hline (R)-1-phenylethanol & & & & + & \\
\hline$(4 S, 5 S)$-2,2,4-triethyl-5-methyl-1,3-dioxolane & & & & & + \\
\hline$(4 S, 5 S)$-2,4-diethyl-2,5-dimethyl-1,3-dioxolane & & & & & + trace \\
\hline $\begin{array}{l}(2 R / S, 4 S, 5 S) \text { - and }(2 R / S, 4 R, 5 R) \text {-4-ethyl-5-methyl- } \\
\text { 2-(1-methylethyl)-1,3-dioxolane }\end{array}$ & & & & & + \\
\hline $\begin{array}{l}(2 R / S, 4 S, 5 S)-4 \text {-ethyl-5-methyl-2-(1- } \\
\text { methylpropyl)-1,3-dioxolane }\end{array}$ & & & & & + trace \\
\hline $\begin{array}{l}(2 R / S, 4 S, 5 S)-4 \text {-ethyl-5-methyl-2-(2- } \\
\text { methylpropyl)-1,3-dioxolane }\end{array}$ & & & & & + trace \\
\hline
\end{tabular}

TABLE 2: Compounds associated with metasternal gland secretions of different triatomine species emitted in different behavioural contexts (references cited in brackets).

\begin{tabular}{|c|c|c|c|c|c|}
\hline & $\begin{array}{c}\text { D. maxima } \\
\text { (disturbed adults: [27]) }\end{array}$ & $\begin{array}{c}\text { T. infestans } \\
\text { (disturbed adults: [30]) }\end{array}$ & $\begin{array}{l}\text { T. infestans } \\
\text { (mating: [30]) }\end{array}$ & $\begin{array}{c}R . \text { prolixus } \\
\text { (female calling: }[16] \text { ) }\end{array}$ & $\begin{array}{c}\text { R. prolixus } \\
\text { (mating: }[16] \text { ) }\end{array}$ \\
\hline 2-butanone & & + & & + & \\
\hline 2-pentanone & & & & + & + \\
\hline 3-pentanone & & + & + & & \\
\hline 3-methyl-2-hexanone & + & & & & \\
\hline (S)-2-butanol & & & & + & \\
\hline 2-methyl-3-buten-2-ol & & & & & + \\
\hline 3-methyl-2-butanol & & & & + & \\
\hline (S)-2-pentanol & & & & + & \\
\hline 2-methyl -1-butanol & & + & & + & + \\
\hline
\end{tabular}


adults of these species $[30,34,47]$. In $T$. infestans, the metasternal glands produce a number of volatiles, including the main component 3-pentanone, which was detected in the odours from copulating pairs [30]. This suggests that T. infestans may use this and possibly other compounds for signalling during mating. The quantities of 3-pentanone in the metasternal glands of T. infestans varied between 10 and $100 \mu \mathrm{g}$ per adult [30], whereas other compounds of the secretion such as 2-methyl-1-butanol and 3-pentanol were present at 1 and $10 \mu \mathrm{g}$ per insect, and 3-hexanol between 0.1 and $1 \mu \mathrm{g}$ per insect. Surprisingly, no apparent differences were found in the composition of the scent produced by these glands between males and females [30]. More recently, further compounds have been identified from two triatomine species, including the acetal $(4 S, 5 S)$-2,2,4-triethyl-5-methyl1,3-dioxolane and related compounds [37, 48]. Occlusion of female metasternal gland orifices resulted in a significant decrease in copulation frequency and prevented the male aggregation behaviour described for this species, suggesting that metasternal gland odours mediate the sexual behaviour of $T$. infestans [15]. Because the attractiveness of mating pairs decreased after occluding female metasternal glands, it was suggested that females emit volatile compounds that promote both copulation and male aggregation behaviour. Similar results were obtained with $R$. prolixus, in which occlusion of male or female metasternal gland orifices induced a decrease in copulation success [16]. Recently, Pontes and Lorenzo [47] have shown that the occlusion of $R$. prolixus female metasternal glands also prevented male aggregation around mating pairs, whereas the occlusion of male metasternal glands did not affect male aggregation. In addition, occlusion experiments also showed that Brindley's gland products are not required for normal mating and male aggregation [15]. In sum, these experiments suggest that volatile compounds from metasternal glands may be among the key signals used in mating interactions.

The metasternal glands of $R$. prolixus produce a variety of volatile compounds, including at least 12 ketones and alcohols. Of these, the most abundant are 2-methyl-3-buten2-ol, 2-pentanol, (E)-2-methyl-3-penten-2-ol, 4-methyl-3penten-2-ol, and the enantiomers of 4-methyl-3-penten-2-ol [16]. Further analysis suggested that the minor compounds 2-butanol, 2-pentanol, 4-methyl-2-pentanol, and 3-hexanol were produced as the $(S)$-enantiomers, whereas 4-methyl-3penten-2-ol (mesityl alcohol) was a mixture of the $(R)$ - and (S)-enantiomers. As with T. infestans, the metasternal gland components of male and female $R$. prolixus appeared to be the same. For $R$. prolixus, these volatile compounds were also detected in the odours of virgin male and female bugs [16], with detection being more frequent from headspace odours from females. Furthermore, females released these substances more frequently during the early hours of the scotophase. In addition, their detection, albeit in limited quantities (e.g., 10-100 pg for 2-pentanol), over copulating pairs of $R$. prolixus suggests that these compounds may be involved in sexual communication [16]. Interestingly, 2methyl-1-butanol is the most consistently detected compound found over mating pairs, even though it is not the most abundant product of metasternal gland secretions.
The metasternal gland secretions of T. brasiliensis were found to contain at least 16 ketones, acetals, and alcohols [34, 37, 48], with 3-pentanone being one of the most abundant compounds, as seen for T. infestans [30]. In addition to 3-pentanone, other abundant components included 3-pentanol and (R)-4-methyl-1-heptanol. The configurations of the chiral compounds varied; 2-methyl-1-butanol was present as the $(S)$-enantiomer, whereas 4-methyl-1hexanol, 4-methyl-1-heptanol, and 1-phenylethanol were present as $(R)$-enantiomers, and 3-hexanol and 3-methyl2-hexanol were present in all isomeric forms [34]. GCEAD recordings performed with $T$. brasiliensis showed that male antennae responded to a number of volatile compounds in the metasternal glands of females, including 3pentanone, $(R)$-4-methyl-1-heptanol, (4S,5S)-2,2,4-triethyl5-methyl-1,3-dioxolane, (S)-2-methyl-1-butanol, and $(R)$ 1-phenylethanol [34]. Electrophysiological experiments still need to be carried out with other important vector species such as T. infestans, T. dimidiata, and $R$. prolixus in order to determine which of the components of the secretions have associated receptors on the bugs' antennae.

Paired glandular areas have been described on the intersegmental membrane between abdominal segments 8 and 9 of male T. infestans and Triatoma rubrofasciata $[49,50]$, along with three areas of glandular structures associated with the basal articulatory apparatus in T. rubrofasciata [50]. The identities and roles of the products of these glands have not been determined.

\section{Male Aggregation Signals and Their Emission during Copulation}

The existence of a chemical signal that is released during mating and promotes the aggregation of males around mating pairs has been consistently reported for $R$. prolixus and $T$. infestans $[47,51-53]$. In these species, females were not observed to aggregate around a mating pair, suggesting that female behaviour is not influenced by the presence of copulating pairs $[47,53]$. The mating and aggregation behaviour of males is not consistent across all triatomines. Panstrongylus megistus females are receptive to copulation only once during their imaginal life, perhaps because the genitalia of males and females remain coupled for an extended period, thus preventing mating with other males [54]. In addition, the apparent absence of signals promoting the aggregation of other males around a mating pair contrasts with the behaviour of $T$. infestans and $R$. prolixus [54]. For the latter two species, pairs remain coupled for shorter intervals, allowing subsequent copulations. For example, aggregated males copulate successively with the same female for T. infestans [53], T. brasiliensis [55], and $R$. prolixus [47]. Thus, the aggregation of males could be related to a polyandrous mating system [56].

Copulating $T$. brasiliensis males are known to modify their behaviour in response to the presence of other males [55], with the duration of mating being prolonged in pairs copulating in the presence of other males. In addition, long postcopulatory associations were observed with T. brasiliensis 
and $R$. prolixus males mating in similar circumstances [47, 55]. These postcopulatory associations are likely a form of mate guarding geared towards impeding subsequent copulation by other males [57]. The observation of multiple mating in several triatomine species suggests the likelihood of sperm competition mechanisms, and the possible costs and benefits of multiple mating in triatomines deserve further analysis.

\section{Perspectives}

Recent advances in identifying and determining the roles of chemical signals in triatomine bugs will aid the development of semiochemical tools for controlling these important disease vectors, but much further work needs to be done to determine which specific compounds mediate sexual behaviours, and their precise roles. If synthetic chemicals are shown to attract males, they could find immediate use as baits for traps to monitor and control populations, thereby limiting the transmission of Chagas' disease. Further detailed analyses of gland contents, including the complete identification of minor components, are essential. The compounds identified will then need to be methodically tested in both laboratory and field bioassays to elucidate their roles as mediators of behaviour. These experiments will need to be followed up with practical field bioassays to determine whether these compounds are sufficiently biologically active that they can be used to trap triatomine bugs effectively. The problem is compounded by the fact that these compounds only affect the behaviours of adult bugs and, in many cases, may only affect one sex. Thus, it remains to be seen whether mass trapping males only, or possible pheromonebased mating disruption, could result in effective control of these bugs. Other aspects, such as cost-effectiveness, can only be evaluated once the key compounds are known. However, because control of triatomine bugs hinges on sensitive detection of low-density populations and foci of vectors, even effective methods of monitoring triatomine bugs would represent a major advance in minimizing disease transmission.

\section{Acknowledgments}

This work received financial support from the ANPCyT (PICT 01191 to G. Manrique), CAPES-SETCIP, CONICET, FAPEMIG, FIOCRUZ, INCT de Entomologia Molecular (CNPq), UNDP/World Bank/WHO Special Programme for Research and Training in Tropical Diseases (TDR), and Universidad de Buenos Aires. The authors thank Ms. Lynne Jeffares for editing the manuscript before submission.

\section{References}

[1] C. J. Chagas, "Nova tripanozomíase humana. Estudos sobre a morfologia e ciclo evolutivo do Schizotrypanum cruzi n. gen., n. sp. agente etiológico de nova entidade mórbida do homem," Memórias do Instituto Oswaldo Cruz, vol. 1, pp. 159-218, 1909.

[2] H. Lent and P. Wygodzinsky, "Revision of the triatominae (Hemiptera, Reduviidae), and their significance as vectors of Chagas' disease. Revisión de los triatominae (Hemiptera, Reduviidae) y su significado como vectores del mal de Chagas," Bulletin of the American Museum of Natural History, vol. 163, no. 3, pp. 123-520, 1979.

[3] R. Zeledón and J. E. Rabinovich, "Chagas' disease: an ecological appraisal with special emphasis on its insect vectors," Annual Review of Entomology, vol. 26, pp. 101-133, 1981.

[4] J. Coura and J. Dias, "Epidemiology, control and surveillance of Chagas disease: 100 years after its discovery," Memorias do Instituto Oswaldo Cruz, vol. 104, no. 1, pp. 31-40, 2009.

[5] L. Cruz-López, E. Malo, J. Rojas, and E. Morgan, "Chemical ecology of triatomine bugs: vectors of Chagas disease," Medical and Veterinary Entomology, vol. 15, no. 4, pp. 351-357, 2001.

[6] P. G. Guerenstein and C. R. Lazzari, "Host-seeking: how triatomines acquire and make use of information to find blood," Acta Tropica, vol. 110, no. 2-3, pp. 148-158, 2009.

[7] A. Hase, "Beobachtungen an venezolanischen triatoma-arten, sowie zur allgemeinen Kenntnis der Familie der Triatomidae (Hemipt.-Heteropt.) —Beiträge zur experimentellen Parasitologie 8," Zeitschrift für Parasitenkunde, vol. 4, no. 4, pp. 585-652, 1932.

[8] M. M. Lima, P. Jurberg, and J. R. D. Almeida, "Behavior of triatomines (Hemiptera: Reduviidae) vectors of Chagas' disease I. Courtship and copulation of Panstrongylus megistus in the laboratory," Memorias do Instituto Oswaldo Cruz, vol. 81, no. 1, pp. 1-5, 1986.

[9] C. M. O. Sordillo and J. R. de Almeida, "Comportamento de corte e cópula de Triatoma pseudomaculata Correa \& Spinola, 1964 (Hemiptera: Reduviidae) sob condições de laboratório," Anais da Sociedade Entomológica do Brasil, vol. 17, pp. 47-69, 1988.

[10] J. C. Rojas, E. A. Malo, A. Gutierrez Martinez, and R. N. Ondarza, "Mating behavior of Triatoma mazzottii Usinger (Hemiptera, Reduviidae) under laboratory conditions," Annals of the Entomological Society of America, vol. 83, no. 3, pp. 598-602, 1990.

[11] J. Rojas and L. Cruz-López, "Sexual behavior in two species of Triatoma phyllosoma complex (Hemiptera: Reduviidae) under laboratory conditions," Journal of Medical Entomology, vol. 29, no. 1, pp. 13-18, 1992.

[12] G. Manrique and C. R. Lazzari, "Sexual behaviour and stridulation during mating in Triatoma infestans (Hemiptera: Reduviidae)," Memórias do Instituto Oswaldo Cruz, vol. 89, no. 4, pp. 629-633, 1994.

[13] F. Roces and G. Manrique, "Different stridulatory vibrations during sexual behaviour and disturbance in the blood-sucking bug Triatoma infestans (Hemiptera: Reduviidae)," Journal of Insect Physiology, vol. 42, no. 3, pp. 231-238, 1996.

[14] G. Manrique and P. E. Schilman, "Two different vibratory signals in Rhodnius prolixus (Hemiptera: Reduviidae)," Acta Tropica, vol. 77, no. 3, pp. 271-278, 2000.

[15] J. G. Crespo and G. Manrique, "Mating behavior of the hematophagous bug Triatoma infestans: role of Brindley's and metasternal glands," Journal of Insect Physiology, vol. 53, no. 7, pp. 708-714, 2007.

[16] G. B. Pontes, B. Bohman, C. R. Unelius, and M. G. Lorenzo, "Metasternal gland volatiles and sexual communication in the triatomine bug, Rhodnius prolixus," Journal of Chemical Ecology, vol. 34, no. 4, pp. 450-457, 2008.

[17] L. Cocchiararo-Bastias, S. Mijailovsky, G. CalderonFernández, A. N. Lorenzo Figueiras, and M. Juárez, "Epicuticle 
lipids mediate mate recognition in Triatoma infestans," Journal of Chemical Ecology, vol. 37, no. 3, pp. 246-252, 2011.

[18] C. R. Lazzari, "Circadian organization of locomotion activity in the haematophagous bug Triatoma infestans," Journal of Insect Physiology, vol. 38, no. 11, pp. 895-903, 1992.

[19] A. C. R. Vitta, Comportamento Sexual de Triatoma brasiliensis (Reduviidae: Triatominae), Fundação Oswaldo Cruz, Belo Horizonte, Brazil, 2009.

[20] G. B. Pontes, Comportamento Sexual de Rhodnius prolixus, Fundação Oswaldo Cruz, Belo Horizonte, Brazil, 2010.

[21] A. V. Antich, "Attraction by smell in nymphs and adults of Rhodnius prolixus (Stal)," Revista do Instituto de Medicina Tropical de Sao Paulo, vol. 10, no. 4, pp. 242-246, 1968.

[22] D. P. Neves and E. Paulini, "Atração sexual em Panstrongylus megistus e Triatoma infestans (Hemiptera, Reduviidae) por feromônio," Revista Brasileira de Entomologia, vol. 25, pp. 301306, 1981

[23] R. N. Ondarza, A. Gutiérrez-Martínez, and E. A. Malo, "Evidence for the presence of sex and aggregation pheromones from Triatoma mazzottii (Hemiptera: Reduviidae)," Journal of economic entomology, vol. 79, no. 3, pp. 688-692, 1986.

[24] R. N. Ondarza, A. Gutierrez-Martinez, E. A. Malo, and J. C. Rojas, "Aphrodisiac activity of the sexual pheromone of Triatoma mazzottii Usinger," Southwestern Entomologist, vol. 12, no. 4, pp. 327-333, 1987.

[25] J. C. Rojas, A. Ramirez-Rovelo, and L. Cruz-López, "Search for a sex pheromone in Triatoma mazzottii (Hemiptera: Reduviidae)," Journal of Medical Entomology, vol. 28, no. 3, pp. 469-470, 1991.

[26] A. Fontan, P. G. Audino, A. Martinez et al., "Attractant volatiles released by female and male Triatoma infestans (Hemiptera: Reduviidae), a vector of chagas disease: chemical analysis and behavioral bioassay," Journal of Medical Entomology, vol. 39, no. 1, pp. 191-197, 2002.

[27] P. G. Guerenstein and P. M. Guerin, "A comparison of volatiles emitted by adults of three triatomine species," Entomologia Experimentalis et Applicata, vol. 111, no. 2, pp. 151-155, 2004.

[28] C. J. Schofield, "Demonstration of isobutyric acid in some triatomine bugs," Acta Tropica, vol. 36, no. 1, pp. 103-105, 1979.

[29] J. P. Ward, "A comparison of the behavioural responses of the haematophagous bug, Triatoma infestans, to synthetic homologues of two naturally occurring chemicals (n- and isobutyric acid)," Physiological Entomology, vol. 6, no. 3, pp. 325-329, 1981.

[30] G. Manrique, A. C. R. Vitta, R. A. Ferreira et al., "Chemical communication in chagas disease vectors. Source, identity, and potential function of volatiles released by the metasternal and Brindley's glands of Triatoma infestans adults," Journal of Chemical Ecology, vol. 32, no. 9, pp. 2035-2052, 2006.

[31] C. J. Schofield, “The behaviour of Triatominae (Hemiptera: Reduviidae): a review," Bulletin of Entomological Research, vol. 69, no. 03, pp. 363-379, 1979.

[32] G. M. Vazquez-Prokopec, L. A. Ceballos, P. L. Marcet et al., "Seasonal variations in active dispersal of natural populations of Triatoma infestans in rural north-western Argentina," Medical and Veterinary Entomology, vol. 20, no. 3, pp. 273-279, 2006.
[33] C. A. Zacharias, G. B. Pontes, M. G. Lorenzo, and G. Manrique, "Flight initiation by male Rhodnius prolixus is promoted by female odors," Journal of Chemical Ecology, vol. 36, no. 4, pp. 449-451, 2010.

[34] A. C. R. Vitta, B. Bohman, C. R. Unelius, and M. G. Lorenzo, "Behavioral and electrophysiological responses of Triatoma brasiliensis males to volatiles produced in the metasternal glands of females," Journal of Chemical Ecology, vol. 35, no. 10, pp. 1212-1221, 2009.

[35] R. B. Barrozo, G. Manrique, and C. R. Lazzari, "The role of water vapour in the orientation behaviour of the bloodsucking bug Triatoma infestans (Hemiptera, Reduviidae)," Journal of Insect Physiology, vol. 49, no. 4, pp. 315-321, 2003.

[36] M. Rossiter and B. W. Staddon, "3-Methyl-2-hexanone from the triatomine bug Dipetalogaster maximus (Uhler) (Heteroptera; Reduviidae)," Experientia, vol. 39, no. 4, pp. 380381,1983

[37] B. Bohman, A. Tröger, S. Franke, M. G. Lorenzo, W. Francke, and C. R. Unelius, "Structure elucidation and synthesis of dioxolanes emitted by two Triatoma species (Hemiptera: Reduviidae)," Journal of Natural Products, vol. 74, no. 4, pp. 690-694, 2011.

[38] J. Carayon, R. L. Usinger, and P. Wygodzinsky, "Notes on the higher classification of the Reduviidae, with the description of a new tribe of the Phymatinae," Revue de Zoologie et Botanique Africaine, vol. 57, pp. 256-281, 1958.

[39] B. W. Staddon, "The scent glands of heteroptera," Advances in Insect Physiology, vol. 14, pp. 131-157, 1983.

[40] C. J. Schofield and C. P. Upton, "Brindley's scent glands and the metasternal scent glands of Panstrongylus megistus (Hemiptera, Reduviidae, Triatominae)," Revista Brasileira de Biologia, vol. 38, pp. 665-678, 1978.

[41] M. D. H. Brindley, "On the metasternal scent glands of certain Heteroptera," Transactions of the Royal Entomological Society of London, vol. 78, no. 2, pp. 199-208, 1930.

[42] C. Weirauch, "Metathoracic glands and associated evaporatory structures in Reduvioidea (Heteroptera: Cimicomorpha), with observation on the mode of function of the metacoxal comb," European Journal of Entomology, vol. 103, no. 1, pp. 97$108,2006$.

[43] A. C. R. Vitta, J. E. Serrão, E. R. Lima, and E. F. Vilela, “The Metasternal and Brindley's Glands of Triatoma brasiliensis Neiva (Hemiptera: Reduviidae)," Neotropical Entomology, vol. 38, no. 2, pp. 231-236, 2009.

[44] M. Kälin and F. M. Barrett, "Observations on the anatomy, histology, release-site, and function of Brindley's gland in the blood-sucking bug Rhodnius prolixus," Annals of the Entomological Society of America, vol. 68, pp. 126-134, 1975.

[45] J. C. Rojas, E. Rios-Candelaria, L. Cruz-López et al., "A reinvestigation of Brindley's gland exocrine compounds of Rhodnius prolixus (Hemiptera: Reduviidae)," Journal of Medical Entomology, vol. 39, no. 2, pp. 256-265, 2002.

[46] L. Cruz Lopez, E. D. Morgan, and R. N. Ondarza, "Brindley's gland exocrine products of Triatoma infestans," Medical and Veterinary Entomology, vol. 9, no. 4, pp. 403-406, 1995.

[47] G. B. Pontes and M. G. Lorenzo, "Female metasternal gland odours mediate male aggregation in Rhodnius prolixus, a 
triatomid bug," Medical and Veterinary Entomology, vol. 26, no. 1, pp. 33-36, 2012.

[48] C. R. Unelius, B. Bohman, M. G. Lorenzo, A. Tröger, S. Franke, and W. Francke, "(4 S,5 S)-2,2,4-Triethyl-5-methyl1,3-dioxolane: a new volatile released by a triatomine bug," Organic Letters, vol. 12, no. 24, pp. 5601-5603, 2010.

[49] R. Barth, "The ectodermal gland of the copulatory system of Triatoma infestans (Heteroptera, Triatominae)," Memorias do Instituto Oswaldo Cruz, vol. 75, no. 3-4, pp. 119-124, 1980.

[50] C. Weirauch, "Glandular Areas Associated with the Male Genitalia in Triatoma rubrofasciata (Triatominae, Reduviidae, Hemiptera) and Other Reduviidae," Memorias do Instituto Oswaldo Cruz, vol. 98, no. 6, pp. 773-776, 2003.

[51] W. F. Baldwin, A. G. Knight, and K. R. Lynn, "Sex pheromone in the insect Rhodnius prolixus (Hemiptera-Reduviidae)," Canadian Entomologist, vol. 103, no. 1, pp. 18-22, 1971.

[52] M. G. de Brito Sánchez, G. Manrique, and C. R. Lazzari, "Existence of a sex pheromone in Triatoma infestans (Hemiptera: Reduvidae): II. Electrophysiological correlates," Memorias do Instituto Oswaldo Cruz, vol. 90, pp. 649-651, 1995.

[53] G. Manrique and C. R. Lazzari, "Existence of a sex pheromone in Triatoma infestans (Hemiptera: Reduviidae): I. Behavioural evidence," Memórias do Instituto Oswaldo Cruz, vol. 90, no. 5, pp. 645-648, 1995.

[54] H. H. R. Pires, M. G. Lorenzo, C. R. Lazzari, L. Diotaiuti, and G. Manrique, "The sexual behaviour of Panstrongylus megistus (Hemiptera: Reduviidae): an experimental study," Memorias do Instituto Oswaldo Cruz, vol. 99, no. 3, pp. 295-300, 2004.

[55] A. C. R. Vitta and M. G. Lorenzo, "Copulation and mate guarding behavior in Triatoma brasiliensis (Hemiptera: Reduviidae)," Journal of Medical Entomology, vol. 46, no. 4, pp. 789795, 2009.

[56] R. Thornhill and J. Alcock, The Evolution of Insect Mating Systems, Harvard University Press, Cambridge, Mass, USA, 1983.

[57] J. Alcock, "Postinsemination associations between males and females in insects: the mate-guarding hypothesis," Annual Review of Entomology, vol. 39, pp. 1-21, 1994. 

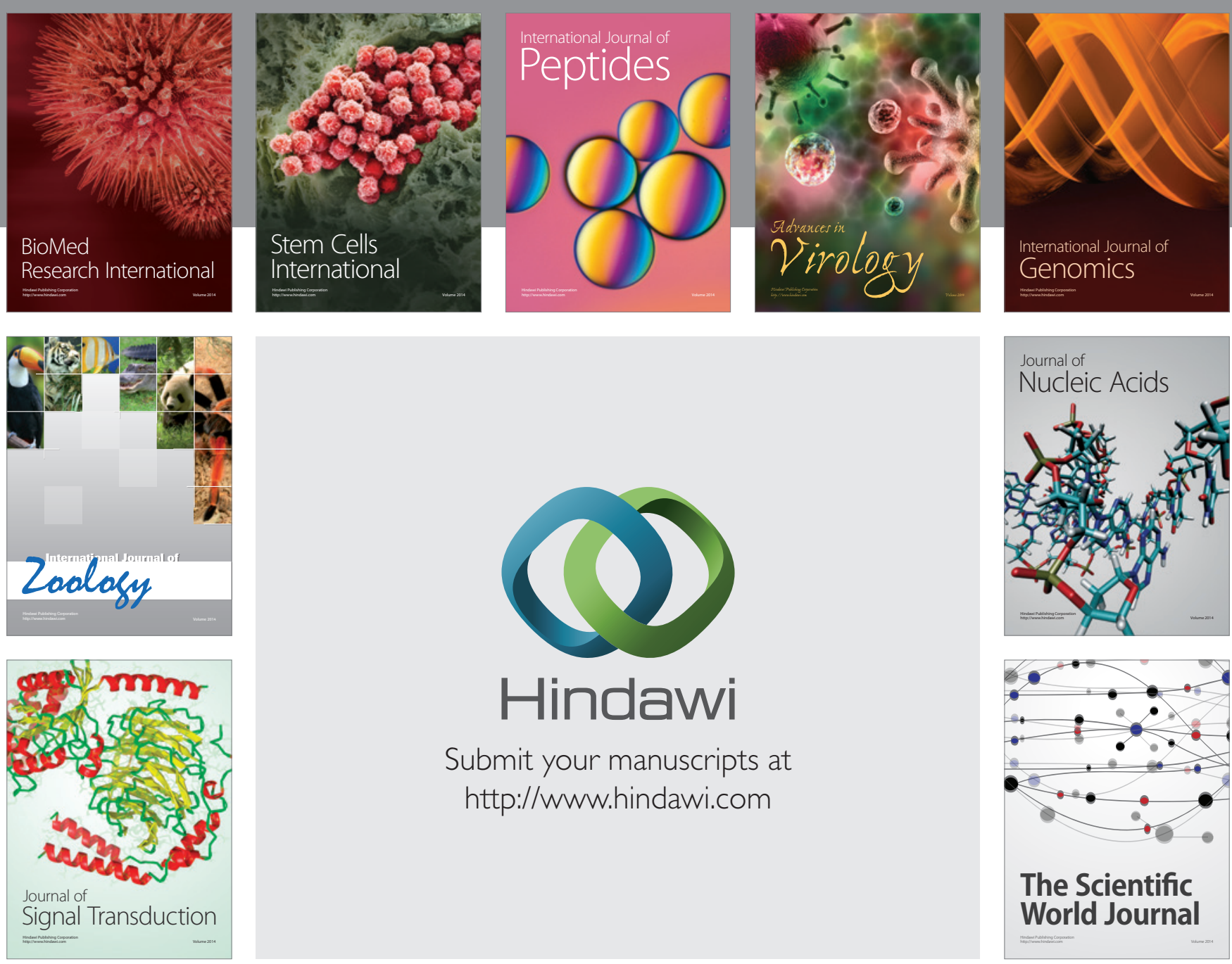

Submit your manuscripts at

http://www.hindawi.com
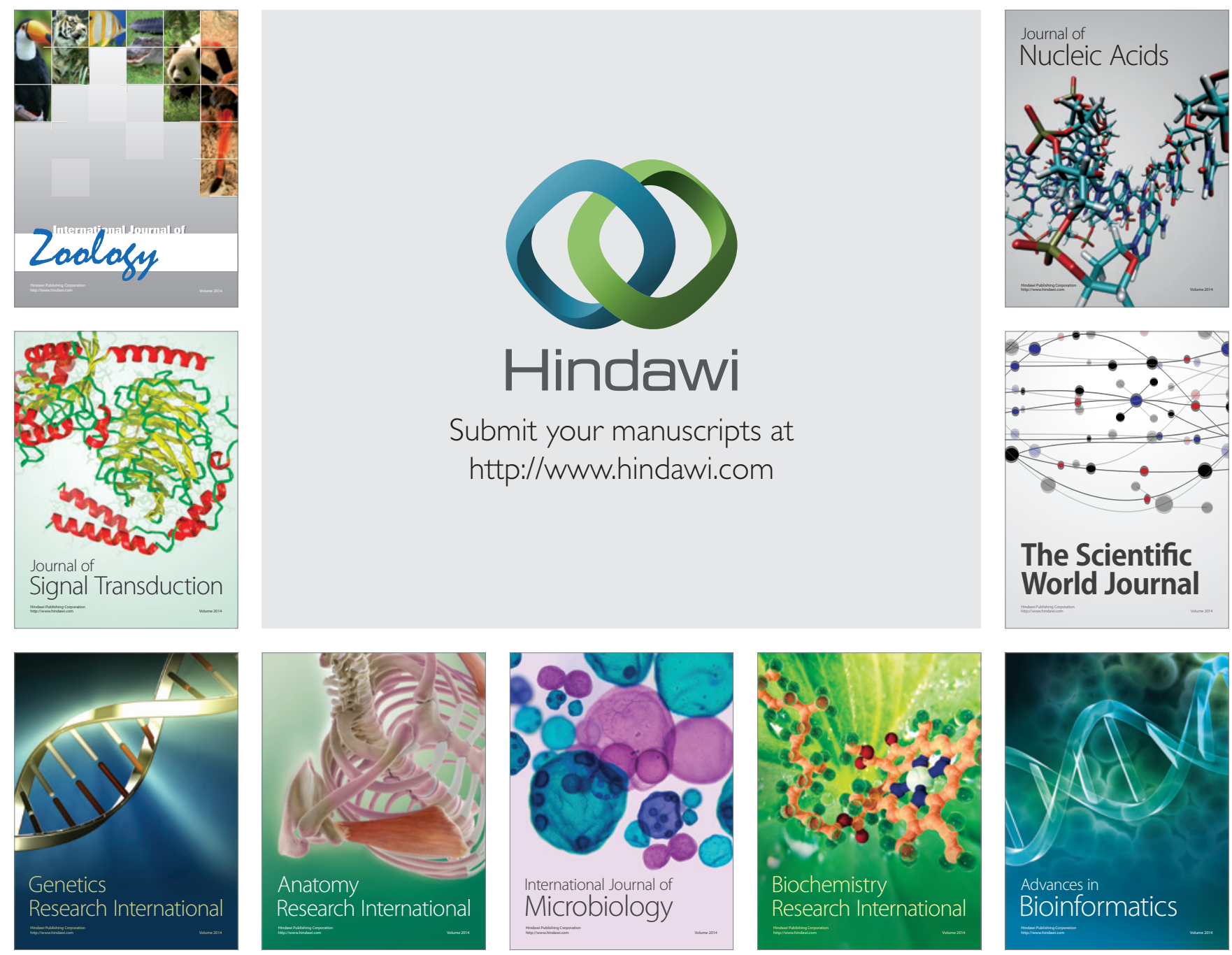

The Scientific World Journal
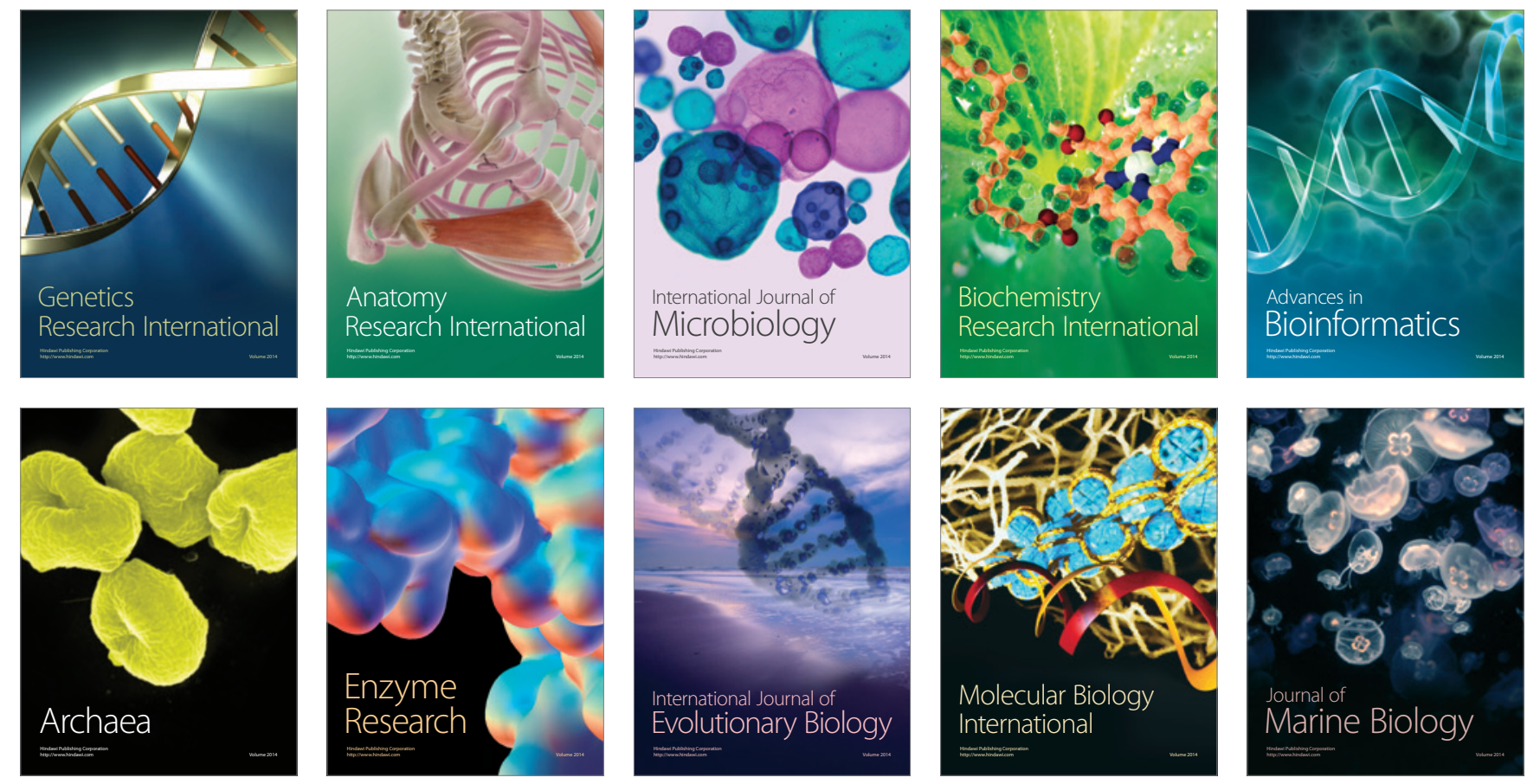